\title{
Temporalidade, historicidade e presença em uma análise do prólogo do Picatrix (séc. XIII)*
}

\author{
Temporality, historicity and presence in an analysis of the prologue of \\ the Picatrix ( $13^{\text {th }}$ Century)
}

\author{
Aline Dias da Silveira \\ aline.d.s@ufsc.br \\ Professora adjunta \\ Universidade Federal de Santa Catarina \\ Rua Di Cavalcanti, 31 - Lagoa da Conceição \\ 88062-187 - Florianópolis - Santa Catarina \\ Brasil
}

\section{Resumo}

O presente artigo tem por objetivo apresentar uma reflexão historiográfica, cujos fundamentos são encontrados nos conceitos de temporalidade e historicidade concebidos por Martin Heidegger. Para tanto, serão apresentados alguns aspectos da obra Ser e tempo (Sein und Zeit), articulados com as interpretações e considerações de outros autores como Reinhart Koselleck, Hans Ulrich Gumbrecht, Cezar Luís Seibt e Valdei Lopes Araújo. Dessa forma, pretende-se contribuir com a construção das categorias historiográficas de temporalidade e historicidade. No segundo momento do texto, à guisa de exemplo, essas categorias serão aplicadas na análise de um documento medieval de astromagia, traduzido do árabe para o castelhano e o latim na corte do rei Afonso $X$ de Castela, o Picatrix. Constata-se que a sociedade medieval, por se tratar de uma "cultura de presença" como propõe Gumbrecht, é um rico laboratório para a compreensão da fluidez das temporalidades e do fenômeno histórico da transculturalidade.

\section{Palavras-chave}

Temporalidade; Historicidade; História Medieval.

\begin{abstract}
The purpose of this article is to present a historical analysis, the fundamentals of which are found in the concepts of temporality and historicity developed by Martin Heidegger. For this, some aspects of the work Being and Time (Sein und Zeit) are presented and articulated, with the interpretations and considerations of other authors such as Reinhart Koselleck, Hans Ulrich Gumbrecht, Cezar Louis Sebt and Valdei Lopes Araújo. This analysis is intended to contribute to the construction of historiographical categories of temporality and historicity. In the second part of the text, these categories are applied in the analysis of a medieval document of astromagic, translated from Arabic into Spanish and Latin at the court of King Alfonso X of Castile, the Picatrix. It appears that, because it is a "presence-culture" as proposed by Gumbrecht, the medieval society is a rich laboratory for understanding the movement of temporalities and the historical phenomenon of transculturality.
\end{abstract}

\section{Keywords}

Temporality; Historicity; Medieval History.

Recebido em: 23/3/2016

Aprovado em: 14/9/2016

\footnotetext{
* Pesquisa financiada pela Coordenação de Aperfeiçoamento de Pessoal de Nível Superior (Capes), através de bolsa de Estágio Pós-Doutoral no Exterior, processo n BEX 0673/15-3 na Universidade Humboldt de Berlim.
} 
O historiador que se interessa por temas como o diálogo intercultural, a diplomacia inter-regional e o lugar social das minorias encontra na Península Ibérica medieval um laboratório denso de objetos e fontes de pesquisa, que abrigam, em sua própria linguagem e historicidade, os enlaçamentos de projetos e de memórias, articulando-os como presença, considerando esse termo no sentido que Heidegger Ihe concede: como presença que vigora por ter sido presente (HEIDEGGER 2005, §76, p. 200-201). ${ }^{1}$ Esta simultaneidade na presença de um presente passado significa que esse passado é um constituinte da consciência do Ser. Por essa perspectiva, é possível viabilizar a abertura para uma nova análise e compreensão do fenômeno histórico da transculturalidade presente nas fontes medievais. E, exatamente por se pretender falar de transculturalidade, tornase necessário transcender os limites temporais e espaciais convencionalmente atribuídos à Idade Média. ${ }^{2}$

A obra de astromagia, o Picatrix, traduzida na corte do rei Afonso $X$ de Castela (1252-1284) é uma destas obras que possibilitam a abertura concreta para a presença do passado que conduz ao fenômeno histórico mais amplo, pois revela a complexidade dos entrelaçamentos temporais de sua historicidade, como apontarei ao longo desta exposição. Por essa via, o presente artigo consiste em uma reflexão historiográfica que busca seus fundamentos nos conceitos de temporalidade e historicidade concebidos por Heidegger. Sem ter a pretensão de aprofundar a interpretação da obra e do pensamento deste filósofo, serão apresentados alguns elementos do livro Ser e Tempo, a fim de indicar uma construção das categorias historiográficas de temporalidade e historicidade a partir desta obra e da releitura da mesma, empreendida por outros autores como Reinhart Koselleck (2012; 2000), Hans Ulrich Gumbrecht (2009; 2010), Cezar Luís Seibt (2010) e Valdei Lopes Araújo (2013). ${ }^{3}$ No segundo momento, aplicarei essas categorias, a título de exemplo, na análise de um trecho do prólogo do Picatrix.

As fontes falam. Quem entre nós ainda não vivenciou uma experiência epifânica ao ler as fontes? Momento em que perguntas, ideias e possibilidades acometem a mente, estimulando o ânimo perante o horizonte de expectativas sobre aquilo que ainda podemos encontrar, levando nossos pensamentos para fora e/ou para dentro de nós: um sentimento de comunhão com a presença do passado. Epifanias que, pelo menos por alguns momentos, nos fazem sonhar,

\footnotetext{
1 "Restos, monumentos, relatos ainda dados constituem "material" possível para a abertura concreta da presença que vigora por ter sido presente. Estes só podem se tornar material historiográfico porque, em seu próprio modo de ser, possuem o caráter de pertencer à história do mundo. E apenas se tornam material na medida em que são previamente compreendidos em sua intramundanidade" (HEIDEGGER 2005, §76, p. 200201). Ou seja, todos esses elementos que nos remetem a um "passado" podem despertar a consciência do Ser para a forma e para o quanto esse "passado" o constitui (dagewesen Dasein).

2 Estou convencida que o caráter de presença do passado nas fontes medievais é tão intenso, que para entendermos uma fonte do século XIII como o Picatrix é necessário não só voltar à história do pensamento neoplatônico, como também à ciência mesopotâmica antiga, como demonstra o trabalho de Pingree (1980). Por este motivo, a utilização do termo medieval neste artigo refere-se a uma percepção e consciência do tempo, bem como utilização do passado presentes nas fontes, e não ao limite temporal e espacial convencional. Dessa forma, sigo as temporalidades e as espacialidades que a fonte me indica.

3 A escolha desses autores legitima-se pela proximidade e suas interpretações com as expectativas do campo da História. No entanto, para um aprofundamento do entendimento filosófico da obra de Heidegger, sugiro as seguintes obras: Figal (2016); Casanova (2015); Stein (2002).
} 
"nos fazem ansiar por saber" como já expressou Hans Ulrich Gumbrecht (2010, p. 148). Não há dúvidas que essa experiência constitui um diálogo com a fonte - não um monólogo. Com o passar do tempo, essa epifania se torna cada vez menos frequente: quanto mais nos aproximamos da fonte, dando-Ihe sentido, mais sua presença deixa de nos afetar. Talvez, neste ponto, estejam marcadas as limitações da própria análise histórica, como Martin Heidegger evidenciou, quando rechaçou a utilização do termo História, preferindo o termo historicidade, pois a historicidade para Heidegger é constituinte do Dasein, ${ }^{4}$ Ser/Presença, (2005, §74, p. 188), como melhor explicaremos no decorrer deste artigo.

Ao iniciar a pesquisa com um livro de astromagia do século XIII, o Picatrix, e ler seus prólogos, deparei-me com as diversas possibilidades instigantes de análise desta fonte e a possibilidade que mais me fascinou foi a análise das múltiplas temporalidades explicitamente presentes na obra. Com o termo temporalidades eu pretendia expressar a percepção e experiência humana no tempo. Porém, à guisa de compreender melhor esse "chamado" da fonte, busquei o conceito na obra de Martin Heidegger (1889-1976) Ser e Tempo (2005, edição original alemã 1927). Como resultado ocorreu a constatação de que no pensamento de Heidegger podemos encontrar fundamentos para categorias de análise do fenômeno histórico, os quais, por sua vez, podem recondicionar a interpretação e a escrita da História, pois "as condições que prefiguram a escrita da história não são apenas condições historiográficas, mas são também ontológico-existenciais" (ARAúJO 2013, p. 41).

\section{Temporalidade e historicidade em Heidegger}

Desde o início de sua obra Ser e Tempo, Heidegger está à procura do sentido do Ser, e para ele o Ser deverá ser compreendido a partir do horizonte da temporalidade, do tempo próprio (SEIBT 2010, p. 251). Assim, a temporalidade e a historicidade são muito importantes para a compreensão do ser. Mas qual seria o significado de temporalidade e historicidade para Heidegger? E como essas categorias poderiam nos auxiliar para a compreensão de nossos objetos de pesquisa?

Heidegger, assim como outros historiadores e filósofos de seu tempo, rechaçou a História tradicional. Sua crítica está no entendimento da História como o estudo do ser humano no tempo, como se a História se constituísse do conjunto de sucessões de fatos e ações passadas. O problema que Heidegger via nessa perspectiva é a do desligamento/separação do ser do presente em relação ao passado e - ainda mais grave para a percepção de Heidegger - do rompimento entre o passado e o futuro, pois essas relações seriam necessárias para a cura do Ser e a abertura para o mundo das coisas. Por

\footnotetext{
${ }^{4} \mathrm{Na}$ tradição filosófica alemã anterior a Heidegger, Dasein é um termo utilizado como sinônimo para o vocábulo latino existentia. Heidegger confere ao termo um significado menos vago, já que seu objetivo é a compreensão do Ser pela perspectiva da fenomenologia, distanciando-se da filosofia existencial. Assim, os fundamentos para a constituição do Ser estão na Transcendência, na Temporalidade e na Historicidade (VETTER 2014, p. 246-248). Os tradutores da obra de Heidegger apresentam diversas interpretações para os termos concebidos por Heidegger. Neste artigo, será utilizada a tradução de Márcia Schubach para Dasein, ou seja, pre-sença/presença. Gumbrecht interpreta o Dasein como "ser-no-mundo" na obra Produção de Presença (2010, p. 96).
} 
isso, Heidegger fala de historicidade e não de história, para evidenciar aquela como um fenômeno constituinte do Ser. A historicidade própria possibilitaria que o Ser reconhecesse a natureza de enlaçamento entre o passado e o futuro no acontecer, onde "acontecer" (ARAúJO 2013, p. 39) poderia ser entendido como o fenômeno histórico. Esse entendimento é o que também podemos ler em Koselleck na sua obra Futuro Passado (2012), pois esse passado, tanto para Heidegger como para Koselleck, são as memórias/experiências e esse futuro são as projeções/expectativas, colocando-os no desenvolvimento de uma longa tradição intelectual alemã de relacionar o passado e o futuro, como a obra de Koselleck apresenta.

Ainda nos remetendo a Heidegger, existiriam dois tipos de historicidades segundo o pensador: a imprópria, também mais corrente, e a própria, emancipatória do Ser. Na historicidade imprópria, o Ser se imagina no tempo, numa situação que desvia a consciência da historicidade como um elemento na constituição interna do Ser, ou seja, não percebe que o entrelaçamento do tempo se realiza no próprio Ser (HEIDEGGER 2005, § 73, p. 183-187; ARAúJO 2012, p. 39), ou no mundo do Ser. A historicidade própria é o módulo que temporaliza a temporalidade, isso significa que a historicidade dá medida e referência à temporalidade a partir da vivência humana. Assim, a historicidade própria é a temporalização da fluidez das experiências passadas e das expectativas do futuro efetivadas no acontecer ou fenômeno histórico, constituindo a percepção temporal humana da temporalidade. Pois, para Heidegger, a temporalidade em si não é o tempo físico, mas o processo interno da presença no mundo, o sentido de estar no tempo:

A análise da historicidade da pre-sença busca mostrar que esse ente não é "temporal" porque "se encontra na história", mas, ao contrário, que ele só existe e só pode existir historicamente porque, no fundo de seu ser é temporal. Todavia, a pre-sença deve ser chamada de "temporal" também no sentido de ser e estar no tempo. Mesmo sem uma construção historiográfica dos fatos, a pre-sença, de fato, precisa e se vale de calendário e relógio. Ela faz a experiência do que "com ela" acontece, como acontecendo "no tempo" (HEIDEGGER 2005, § 72, p. 181).

Ou seja, a qualidade "temporal" do Ser não seria determinada por uma força externa, porém, no sentido contrário, pela percepção ou consciência interna do tempo próprio do Ser. Nossa sincronização com o tempo natural por meio de calendários e relógios nos conduziria à sensação de que esses tempos se equivalem. No entanto, a percepção de temporalização do Ser é um processo interno. Cezar Luís Seibt entende, a partir de sua leitura de Heidegger, que tendo descoberto o tempo, o Dasein (traduzido por Márcia Schubach como pre-sença) volta para si mesmo e seu próprio pensar e, a partir do tempo compreendido, pensa a temporalidade de si (SEBT 2010, p. 252). Heidegger compreende quatro constituições existenciais temporais que formariam a estrutura da temporalidade, cada uma dessas poderiam se manifestar de forma própria ou imprópria: 
Compreensão (Verstehen) - é o despertar do Ser para si mesmo e para as possibilidades que podem ser realizadas (VETTER 2014, p. 369). Sua temporalização é a projeção para o futuro. Koselleck utiliza o termo horizonte de expectativas (KOSELLECK 2012, p. 305-327) para expressar na linguagem da tradição historiográfica alemã essa percepção. A manifestação própria da compreensão está na antecipação e a imprópria na espera;

A disposição (Befindlichkeit)- é a disposição mental ou ânimo do Ser de se perceber e ser afetado. Sua temporalização é a afetação pelo passado. Koselleck aproxima-se dessa compreensão pelo termo espaço de experiências. Na historiografia, poderíamos entender sua temporalização como memória no mais amplo sentido. A disposição se manifesta propriamente na repetição e impropriamente no esquecimento;

Decaída (Verfallen) - Cezar Seibt utiliza a palavra decaída para a tradução do termo Verfallen e Márcia Schubach a palavra de-cadência. ${ }^{5}$ Consciente de sua morte e livre da ilusão de eternidade, o Ser estaria pronto para a ação. Assim, sua temporalização (referência) é a consciência da finitude, é o instante, o Augenblick, o ato resolutório. Ao contrário, em sua impropriedade, a decaída manifesta-se pela dispersão. A decaída própria é o instante da decisão tomada a partir da fluidez da projeção para o futuro e da afetação do passado no acontecer presente, é a abertura para o mundo.

Linguagem (Rede)- Prefiro utilizar o sentido de linguagem para o vocábulo alemão Rede na obra de Heidegger (VETTER 2014, p. 344346), recusando a prática corrente de traduzi-lo como "discurso", pois a abrangência do termo linguagem aproxima-se mais do contexto conceitual do pensamento de Heidegger, como já colocou Ernildo Stein (2004), e tem uma maior eficácia na interpretação das fontes históricas, principalmente medievais, como mostrarei adiante. A compreensão, a disposição, e a decaída precisam da linguagem para ser articuladas, possibilitando, assim, a abertura do Ser para o mundo (HEIDEGGER 2005, §68, p. 148).

A articulação e a interação dessas quatro constituições existenciais temporais ativam um processo que nos remete à consciência do próprio Ser, de forma que esse transcenda uma ilusória determinação do mundo sobre si. Na temporalidade, o Ser se projeta no futuro (expectativas, projetos e utopias), retrocede no passado (experiências, memória) que convergem no instante da consciência de si e sua finitude atualizada, por isso a consciência do Dasein (pre-sença) na temporalidade não se restringe apenas ao momento passado.

Em relação ao conceito de historicidade na obra de Heidegger, Valdei Lopes Araújo entende que essa "deveria ser compreendida como a temporalização da temporalidade humana, ou, em outras palavras, a efetivação dessa condição estrutural do humano, o tempo histórico" (ARAÚJO 2013, p. 39). Assim, temos uma definição de historicidade como tempo histórico, a partir da constituição temporal do fenômeno (compreensão, disposição, decaída e linguagem) em uma unidade denominada temporalidade, sendo que o tempo histórico é o que dá referencias (memória, expectativas e vivência) a essa unidade.

\footnotetext{
${ }_{5}^{5}$ Eu prefiro entender Verfallen no sentido de entregar-se, pois o Ser se entregaria à certeza de sua finitude, marcada pelo seu nascimento e sua morte, em consequência, perceberia que somente pode contar consigo mesmo para sua própria transcendência do mundo. No entanto, continuarei utilizando o termo dos autores anteriores por reconhecimento ao estado da arte.
} 
Um passo adiante: na análise de um fenômeno histórico, se deveria considerar a unidade constituída pela relação das expectativas, das experiências, da consciência e da linguagem, onde a linguagem é a fonte que presentifica o passado. Assim, a linguagem, (ou o discurso como muitos a interpretam) não é o todo, mas o meio pelo qual se pode acessar a temporalidade e a compreensão do fenômeno histórico. A fonte possibilita a abertura para o desvendamento do mundo ou, na linguagem historiográfica, da problemática colocada.

\section{Experiências e expectativas}

A considerar essa relação, a utilização das categorias experiência e expectativa como constituintes da temporalidade parece extremamente pertinente, quando aplicadas à análise da fonte com o objetivo de compreender o fenômeno histórico. Koselleck afirma que a história em si, como objeto de pesquisa, ou a teoria da história ou a filosofia da história trata de categorias transcendentais, ou seja, meta-históricas: "tornou-se impossível, embora ainda se tente com freqüência, tratar cientificamente a história sem que se tenha uma ideia precisa das categorias pelas quais ela se expressa" (KOSELLECK 2012, p. 305). Com essas palavras, o autor legitima a utilização absolutamente necessária das categorias experiência e expectativa, as quais indicariam uma condição humana universal e se equivaleriam às categorias de tempo e espaço. Em outras palavras, elas remeteriam a um dado antropológico ${ }^{6}$ prévio, sem o qual a história não seria, ou "não poderia sequer ser imaginada" (KOSELLECK 2012, p. 307-308). Koselleck esclarece essa sua tese:

experiência e expectativa são duas categorias adequadas para nos ocuparmos com o tempo histórico, pois elas entrelaçam passado e futuro. São adequadas também para se tentar descobrir o tempo histórico, pois, enriquecidas de seu conteúdo, elas dirigem as ações concretas no movimento social e político (KOSELLECK 2012, p. 308).

A experiência seria o passado presente, constituída tanto das acumulações de ações pessoais como coletivas. A expectativa seria um futuro presente, ligada ao mesmo tempo à pessoa e ao interpessoal, também se realizaria no hoje, voltada para o ainda não experimentado, para o que apenas pode der previsto. Elas seriam partes constituintes de um presente, mas não seriam simétricas. Passado e futuro jamais chegariam a coincidir, pois a expectativa não poderia ser totalmente extraída da experiência. Por sua vez, a experiência estaria completa na medida em que suas causas são passadas, enquanto a experiência futura, antecipada como expectativa, se decomporia em múltiplos momentos temporais. Esses dois conceitos remeteriam à temporalidade humana e, metahistoricamente, à temporalidade da história (KOSELLECK 2012, p. 309-310).

O componente indispensável ao desenvolvimento da tese do autor é o espaço, pois o tempo só pode ser expresso na linguagem através de metáforas

\footnotetext{
${ }^{6}$ A ideia de um "dado antropológico" precisa ser entendida dentro do contexto da "Historische Anthropologie", uma perspectiva alemã de pesquisa transdisciplinar nas ciências humanas. Uma obra interessante que apresenta um debate internacional sobre essa linha de pesquisa é Rüsen (1999).
} 
espaciais, o que também realça a ideia de presença temporal. Por esse motivo, Koselleck utiliza a metáfora "espaço de experiência" (Erfahrungsraum) e "horizonte de expectativa" (Erwartungshorizont), para mostrar que a presença do passado é diferente da presença do futuro. A experiência proveniente do passado é espacial, se acumula para formar estratos de tempos (Zeitschichten) anteriores que estão simultaneamente presentes. Por isso, o autor diz que a experiência salta por cima dos tempos. A experiência "não cria continuidade no sentido de uma elaboração aditiva do passado. A expectativa está para a linha por trás da qual se abre o futuro, um novo espaço de experiências que não pode ainda ser contemplado" (KOSELLECK 2012, p. 311). Não se trataria, aqui, de conceitos opostos, pelo contrário, eles indicariam maneiras diversas de ser, e da tensão que daí resulta poderia ser deduzido algo como tempo histórico. Ou seja, a tensão entre experiência e expectativa suscita diversamente novas soluções, constituindo o tempo histórico (KOSELLECK 2012, p. 312-313). Percebe-se claramente que o tempo histórico definido por Koselleck tem seu fundamento no conceito de historicidade de Heidegger.

Koselleck atribui às categorias espaço de experiência e horizonte de expectativa o valor de absolutamente indispensáveis. Com essa perspectiva, o autor exemplifica a operacionalização da análise do fenômeno histórico ou tempo histórico a partir dessas categorias, principalmente, quando dedica a última parte do capítulo quatorze da obra Futuro Passado à comparação da relação entre experiência e expectativa na época pré-moderna (medieval) e moderna. Com isso o autor pretende fundamentar a tese de que, na modernidade, a distância entre experiências e expectativas aumenta progressivamente. Diante das possibilidades abertas por Koselleck, aplico essas categorias na análise do Picatrix, a considerar que a fonte enquanto linguagem é a articuladora de ambas as categorias, tornando possível a abertura da presença para o fenômeno histórico.

\section{Presença}

Presença é um conceito que vem sendo desenvolvido e utilizado nas últimas décadas na área da teoria da história e filosofia da história, principalmente na academia norte-americana (RUNIA 2006, 2014; FROEYMAN 2012; TELLES 2015), e colocado no debate crítico em relação às ideias de representação e sentido do passado. Hans Ulrich Gumbrecht insere-se nesse debate com a obra Produção de Presença (2010), cuja primeira edição em inglês e alemão ocorreu em 2004. Em sua crítica ao que ele chama de "existencialismo lingüístico" sobre a suposta incapacidade da linguagem de se referir às coisas do mundo, ele considera que na experiência da nossa relação com as coisas (especialmente artefatos culturais) não seria apenas uma relação de sentido, mas de presença (GUMBRECHT 2009, p. 12), contrariando a metafísica ocidental que separa objeto e sentido. Ele chama a atenção para a presença física da linguagem, sempre dada, mas que foi, dentro da cultura moderna, sistematicamente omitida ou mesmo colocada entre parênteses, e afirma que a linguagem pode produzir epifanias, nas quais o passado é tornado presente (GUMBRECHT 2009, p. 16; 2010, p. 148). Por essa perspectiva, a fonte pode, enquanto linguagem, tornar 
presente o passado, no sentido de suscitar experiências sensoriais de presença. Por exemplo, na experiência de ler em voz alta os versos da Divina Comédia de Dante Alighieri.

Através da convergência entre o conceito de Heidegger do Dasein (presença) e as reflexões feitas por Hans Ulrich Gumbrecht sobre a presença do passado pode-se trazer luz sobre a aplicação desse conceito. Gumbrecht percebe na ideia de linguagem como a casa do Ser/Presença uma forma promissora de compreensão de fenômenos culturais, mas que, quando efetivada, pode vir a ser diferente daquilo que Heidegger quis dizer com estas palavras. Quatro aspectos desta metáfora lhe interessam. Primeiro, ele destaca o fato de que, frequentemente, uma casa torna os seus habitantes mais invisíveis do que visíveis. Assim, a linguagem não atuaria como uma "janela"; a linguagem não seria primordialmente a expressão da presença, com a qual esta linguagem possa ser entrelaçada. Contudo, em segundo lugar, poderíamos considerar a casa como sendo a promessa ou até mesmo garantia da proximidade daqueles que acreditamos nela residirem. Gumbrecht utiliza, então, o exemplo da linguagem do misticismo: "ela pode não tornar o divino completamente presente, e certamente não é uma expressão total do divino, mas ao ler textos místicos alguns de nós sentem-se mais próximos do divino" (GUMBRECHT 2009, p. 20). Em terceiro, o autor coloca que o que mais ele aprecia em relação à metáfora da "linguagem como a casa do Ser" seria a sua denotação espacial. Diferente do clássico paradigma hermenêutico de expressão, "o entendimento da linguagem

192 como "a casa do Ser" (ou como a casa da presença) nos faz imaginar aquele que habita a casa como possuidor de "volume" e que compartilha, assim, o estatuto ontológico das coisas." (GUMBRECHT 2009, p. 20).

\section{Um possível método de análise}

Como pensar, no entanto, a análise da fonte como linguagem que torna presente o passado não por seu potencial epifânico, mas como presença de vigor em seu próprio tempo histórico, por exemplo, o século XIII?

A resposta que encontro para essa questão é a seguinte: dever-seia considerar o enlaçamento dos espaços de experiências e do horizonte de expectativas presente na fonte, afinal, sem essas categorias a história nem poderia ser imaginada, como afirma Koselleck. Por essa via, o passado pode ser compreendido como fenômeno histórico. E, retornando à proposta de Gumbrecht, deveríamos sempre reconhecer a sociedade medieval como uma cultura de presença.

Gumbrecht define dois tipos de culturas referentes à presença do passado no presente: as "culturas de sentido", como a nossa cultura moderna, e as "culturas de presença" (GUMBRECHT 2010, p. 105), como a medieval. Por essa via, a compreensão da cultura medieval pode ser facilitada e impulsionada para outros entendimentos da noção de história e memória, na qual a presença do passado é manifesta cotidianamente e ritualisticamente. Gumbrecht coloca: 
Uma cultura de presença, em contraste, integrará igualmente a existência espiritual e física em sua autorreferência humana (pense, por exemplo, na obsessão com a "ressurreição espiritual e corporal" na Cristandade medieval). Segundo, segue desta distinção inicial que em culturas de presença os seres humanos se consideram como parte do mundo de objetos ao invés de serem ontologicamente separados dele. Terceiro, e em um nível mais alto de complexidade, a existência humana, em uma cultura de sentido, se revela e se realiza em contínuas e progressivas tentativas de transformar o mundo ("ações") que estão baseadas nas interpretações das coisas e na projeção dos desejos humanos no futuro. Este impulso para a mudança e a transformação está ausente nas culturas de presença nas quais os seres humanos buscam apenas inscrever seu comportamento no que consideram ser estruturas e regras de uma determinada cosmologia (chamamos de "rituais" os quadros situacionais para que tais tentativas correspondam a quadros cosmológicos mais amplos) (GUMBRECHT 2009, p. 13).

Não é novidade nos estudos medievais a constatação dessas formas diversas de relacionar-se com o passado, as quais poderíamos chamar no ocidente de relação pré-moderna e moderna, como os vários medievalistas já evidenciaram. ${ }^{7}$ A novidade na interpretação de Gumbrecht, aproximandose da proposta de Koselleck, é que essa diferença não ocorre simplesmente pelo passar sucessivo e evolutivo do tempo, mas em função do fenômeno mais complexo da medida da fluidez de expectativas e experiências da presença na temporalidade, transformando também - e inevitavelmente - as perspectivas das ciências humanas e, talvez, esse aspecto seria aquele que mais os aproximam de Heidegger e seu conceito ontológico de historicidade. ${ }^{8}$

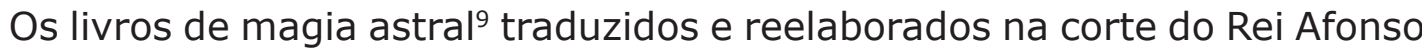
$X$ de Castela manifestam a reunião de suas temporalidades na articulação de linguagem filosófica e mágica que, indubitavelmente, abriga a presença cósmica, espiritual e física. Essa presença é construída na obra a partir das experiências milenares e contemporâneas, bem como das expectativas políticas do reino de Castela em tornar-se hegemônico no espaço ibérico e socialmente harmônico no sentido neoplatônico da fonte, ou seja, hierárquico e estável.

\footnotetext{
7 Exemplo de algumas obras: LE GOFF, Jacques. O Maravilhoso e o Cotidiano no Ocidente Medieval (1983); LE GOFF, Jacques. O imaginário Medieval (1994); DUBY, George. As Três Ordens ou o Imaginário do Feudalismo (1994); GUREVICH, Aron. I.. As Categorias da Cultura Medieval (1991); ZUMTHOR, Paul. La medida del mundo (1984); BAKTHIN, Mikail. A Cultura Popular na Idade Média e no Renascimento (1987).

80 interessante é que ambos os autores manifestam suas próprias expectativas. No caso de Gumbrecht, outra medida dessa fluidez poderia aproximar a linguagem em suas múltiplas e tensionadas convergências com a presença. Isso seria um meio em e através do qual poderíamos esperar uma reconciliação (ou pelo menos uma reaproximação) entre o Ser (Dasein) e os objetos no mundo (2009, p.20). No caso de Koselleck, o autor tem a visão de que poderia acontecer uma relação entre experiências e expectativas que viesse readquirir espaço em nossa sociedade, onde quanto maior a experiência, tanto mais cautelosa, mas também tanto mais aberta a expectativa, diferenciando-se da relação atual do progresso, na qual as experiências são pouco consideradas em função da rapidez das transformações e a grande exigência em relação às expectativas. "Para além de qualquer ênfase, ter-se-ia então alcançado o final da modernidade, no sentido de progresso otimizante" (2012, p. 327).

Sobre a percepção ontológica de Heidegger, o filósofo coloca: "A pre-sença de fato sempre possui a sua "história", e pode possuí-la porque o ser deste ente se constitui de historicidade. Esta tese deve se justificar com vistas à exposição do problema ontológico da história enquanto problema existencial.", HEIDEGGER, Martin. Ser e tempo (2005, §74, p. 188)

9 Outros livros de astromagia traduzidos na corte de Afonso X e publicados: Astromagia (Ms.Reg.lat.1283a) (1992); Lapidario. Según el manuscrito escurialense h.I 15(1981).
} 
Perante as relações apresentadas neste artigo, proponho a análise da fonte em duas perspectivas. Na primeira, são articuladas as temporalizações, as expectativas e experiências, tornando-as fontes históricas, identificando o fenômeno histórico a partir de sua historicidade. Por essa perspectiva, a visão de mundo da fonte serve de acesso para compreender a sua temporalidade e o que se torna presente na linguagem medieval. Na outra perspectiva, são utilizados conceitos e categorias exteriores à fonte, concernentes às ciências humanas e à filosofia. Trata-se, como lembra Koselleck (2012, p. 305), de trabalhar metodologicamente, e de forma consciente, com conceitos ligados à fonte, bem como às categorias científicas do conhecimento. Ambas as perspectivas devem ser trabalhadas concomitantemente.

A considerar que o objetivo desse artigo consiste em uma modesta reflexão historiográfica possível, serão apresentadas algumas possibilidades de análise a partir de um trecho do prólogo da fonte:

Pelo louvor e pela glória do altíssimo e todo-poderoso Deus, o qual revela aos seus predestinados as ciências secretas, e também esclarece aos doutores latinos que desconheciam este livro, que os antigos filósofos editaram. Alfonso, pela graça de Deus ilustrísimo rei da Espanha e de toda Andaluzia, ordenou a tradução deste livro, com grande estudo e máximo cuidado, do árabe ao espanhol, cujo nome é Picatrix. Este é o trabalho perfeito terminado no ano do Senhor 1256, de Alexander 1568, de Cesar 1295 e dos árabes 655. O sábio filósofo, nobre e honrado Picatrix fez este livro a partir da compilação de mais de duzentos livros de filosofia, no qual tem o seu próprio nome nomeado. ${ }^{10}$

O fenômeno histórico que esse trecho presentifica é a transculturalidade manifesta no diálogo inter-religioso/cultural, diplomacia/conflitos inter- e intrarregional e o lugar social das minorias. Um caminho possível de análise desse fenômeno seria primeiro entendê-lo como objeto da cultura de presença do passado como categoriza Gumbrecht. Ou seja, "um passado que não passou", ${ }^{11}$ cuja presença quase sensorial, no sentido original latino de prae esse, que o coloca diante dos indivíduos, tornando-o quase tangível. É nesse passado milenar e ainda presente no século XIII que as sociedades medievais (tanto grega, como latinas, e islâmicas) fundamentaram e legitimaram o conhecimento. Por isso, a função explícita do Picatrix está em "revelar" as "ciências secretas" dos filósofos antigos, conhecimento que até mesmo os "doutores latinos" desconheciam. Assim, o fato de esses filósofos antigos serem pagãos ou muçulmanos não deslegitima em nada o valor da obra para o rei cristão. Não há nessas palavras

\footnotetext{
10 Tradução da autora a partir da seguinte versão latina: "Ad laudem et gloriam altissimi et omnipotentis Dei cuius est revelare suis predestinatis secreta scienciarum, et ad illustracionem eciam doctorum Latinorum qui bus est inopia librorum ab antiquis philosophis editorum, Alfonsus, Dei gracia illustrissimus rex Hispanie tociusque Andalucie, precepit hunc librum summo studio summaque diligencia de Arabico in Hispanicum transferri cuius nomen est Picatrix. Hoc autem opus perfectum fuit anno Domini MCCLVI, Alexandri MDLXVIII, Cesaris MCCXCV, et Arabum DCLV. Sapiens enim philosophus, nobilis et honoratus Picatrix, hunc lib rum ex CC libris et pluribus philosophie compilavit, quem suo proprio nomine nominavit." Picatrix. The Latin Version of the Ghayat Al-Hakim (1986, p. 1, linhas 1-6).

${ }_{11}$ WOLF, Christa. Kindheitsmuster. Frankfurt am Main: Suhrkamp, 1989, p. 11: "Das Vergangene ist nicht tot; es ist nicht einmal vergangen. Wir trennen es von uns ab und stellen uns fremd", citada por Jörn Rüsen em RÜSEN, Jörn. Como dar sentido ao passado: questões de meta-história (2009, p. 163-209)
} 
a ideia de conhecimento acumulado, mas revelado, pois a matéria da obra versa sobre o conhecimento essencial da ordem do universo em uma perspectiva neoplatônica, ${ }^{12}$ pela qual o microcosmo (ser humano) tem presente em si o macrocosmo (universo).

O Picatrix, bem como seu texto original chamado Gāyat al-hakīm, é dividido em quatro tratados. Os dois primeiros desenvolvem explicações filosóficas de como se manifestam as leis do universo na relação entre micro e macrocosmo através do princípio neoplatônico de emanação. ${ }^{13}$ Os dois últimos apresentam fórmulas e formas práticas de catalisar essa emanação a partir dos corpos celestes e direcioná-la para algum objetivo através de rituais. O princípio simpático de correspondência e influência dos corpos supralunares (planetas) sobre os corpos sublunares (terrestres) é a base fundamental das práticas, apresentando o caminho de como a força emanada pode ser intensificada, canalizada, direcionada e utilizada (SILVEIRA 2015). A essa prática é dado na fonte o nome de magia.

García Avilés (1999) divide os tratados de "ciências mágicas" da corte afonsina em três tipos: o da magia harraniana, que corresponderia às obras o Picatrix e o Libro de Astromagia, ${ }^{14}$ onde são encontradas invocações, orações e práticas mágicas para atrair o poder dos corpos celestes através de imagens talismânicas gravadas em pedras e anéis. O segundo tipo de magia é chamado pelo autor de salomônico, no qual se encontraria o Liber Razielis, ${ }^{15}$ cuja matéria versa sobre rituais de invocação a anjos, considerados mediadores entre o ser humano e os corpos celestes incorporando princípios da cabala prática, trechos de vários outros textos da tradição hebréia foram incorporados nessa obra. O terceiro tipo de livros seria representado pelo Lapidario $^{16}$ e o Libro de las formas y de las imágenes, os quais não apresentam cerimônias e invocações, mas descreverem as virtudes naturais e ocultas da natureza, principalmente as dos minerais, em relação aos movimentos dos corpos celestes, bem como as imagens mais propícias a talhar sobre os minerais para atrair a força dos planetas. Porém, a biblioteca astromágica da corte afonsina seria bem maior, já que se podem identificar trechos de obras não completamente traduzidas incorporados a obras finalizadas (GARCIA AVILÉS 1999).

Para compreender as experiências constitutivas da obra nesta cultura de presença é necessário ter em mente uma sociedade pautada pela tradição e pela memória, e considerar a tradição textual (egípcia, grega, indiana,

\footnotetext{
12 O texto de Carlos Escudé, Neoplatonismo y pluralismo filosófico Medieval: un enfoque politológico (2011), constitui uma interessante base de discussão sobre o tema do neoplatonismo medieval pela perspectiva dos entrelaçamentos culturais. O desenvolvimento dos argumentos de Escudé demonstra como a busca do conhecimento transcendeu fronteiras espaciais, de identidades religiosas e étnicas, bem como superou os limites da diferença dos idiomas.

13Considerando os três princípios platônicos Uno, intelecto e alma, emanação - em grego proeînai, aporreîn - "é um momento descendente, e é seguida de uma conversão daquilo que foi emanado em direção de sua origem, num momento ascendente. Aquilo que emana do Uno volta-se para o Uno, e produz-se o Intelecto; de modo similar, uma vez que o Intelecto alcança sua perfeição, emana algo de si que, ao converter-se para o Intelecto, produz a Alma. Portanto, duas hipóstases, Intelecto e Alma, procedem hierarquicamente do Uno." (LUPI; GOLLNICK 2008, p. 14).

${ }_{14}$ Astromagia (Ms.Reg.lat.1283a), ed., 1992.

${ }^{15}$ Liber Razielis, (Roma, Biblioteca Vaticana, Ms. Reg. lat. 1300).

${ }^{16}$ Lapidario. Según el manuscrito escurialense h.I 15, ed.1981.
} 
caldéia, árabe) e a tradição filosófica neoplatônica no conteúdo do texto. A partir disso, a obra passa inevitavelmente a ser considerada na temporalidade da translatio studiorum. Esse é o termo utilizado já na Idade Média ${ }^{17}$ para designar o movimento do saber de uma região do mundo para outra. Atualmente, o termo é definido como um movimento que teria se originado já na época helenística, onde textos do oriente médio e próximo fluiriam junto às traduções e reelaborações gregas nas principais capitais do período (PEREIRA 2004, p. 73). Essa tradição de traduções em busca do conhecimento essencial teria na Idade Média se desenvolvido em cidades como Harran no norte da Mesopotâmia (hoje na fronteira da Turquia com o Iraque), Damasco, Basra, Bagdá e dessas para o Mediterrâneo em Palermo, Toledo e Sevilha. De fato, a fluidez deste movimento é muito mais abrangente espacial e temporalmente, se considerarmos as traduções irlandesas, o intercâmbio de intelectuais irlandeses na corte de Carlos Magno (MEEDER 2010), as relações diplomáticas desse com os Califas de Bagdá (DREWS 2009) e as trocas viabilizadas através das Rotas da Seda desde a Antiguidade.

Retornando ao reino de Castela, o fato do Picatrix tratar-se de uma tradução do árabe para o castelhano e latim, feita por uma equipe liderada pelo judeu Yehuda Ben Mose ha-Cohen (DÍES BRASA 1984, p. 31), o remete à experiência de séculos de convivência e de conflitos entre cristãos, judeus e muçulmanos. Como já considerado em outros trabalhos (SILVEIRA 2013; 2014), o tratamento das minorias religiosas na Península Ibérica pelos monarcas muçulmanos e 196 cristãos consiste em relações complexas que mesclam a instrumentalização das identidades culturais em favor dos respectivos projetos políticos com relações pessoais, as quais possuíam na época um sentido e um valor de legitimidade imensamente maior que na modernidade. Dessa forma, o fato de que os mouros e os judeus de Castela estavam sob a proteção de Afonso X significa, na prática, a doação de mesquitas para a comunidade judaica transformá-las em sinagogas em Sevilha, ${ }^{18}$ ou a criação de uma universidade trilíngue na mesma cidade, onde o árabe, o latim e o castelhano foram ensinados. ${ }^{19}$ Por outro lado, significa também que o rei pode tomar o que quiser de seus protegidos e movimentar suas comunidades como bem entender. Indubitavelmente, todas essas experiências constituíram o melhor ambiente para a tradução do Picatrix. No entanto, a obra não é um resultado, mas um elemento na construção do projeto político de Afonso $X$ no caminho de tornar realidade suas expectativas.

\footnotetext{
17 Nos escritos medievais ocidentais a translatio studiorum pertenceria ao movimento da translatio imperii, termo utilizado para designar a transferência da potentia e sapientia do oriente ao ocidente, do Egito, Atenas, Roma à Paris. Otto von Freising estabelece esta relação já no prólogo de sua obra Historia de duabus civitatibus (1157), ver: Otto von Freising. Chronik oder die Geschichte der Zwei Staaten (1960, p. 12-14). No mundo muçulmano, seria o filósofo al-Farabī (século IX) que faria esse tipo de referência ao pensamento filosófico relacionando Atenas à Bagdá, passando antes por Antioquia, Harran e Merv.

$18 \mathrm{Em} 05$ de agosto de 1252, Afonso X doa há Igreja todas as mesquitas que estão em Sevilha, fora três mesquitas que foram doadas aos judeus por seu pai para tornarem-se sinagogas. Ver Diplomatario Andaluz (1991, documento 4, p. 6-7).

19 Em 28 de dezembro de 1254, Alfonso X, na presença dos reis muçulmanos de Granada, Murcia e Niebla, seus vassalos, outorga a fundação dos Estudos e escolas gerais de latim e árabe. Ver Diplomatario Andaluz (1991, documento 142 , p. 152-153).
} 
Os projetos/expectativas que fluem para a obra Picatrix presentificam o desejo de Afonso $X$ de tornar Castela hegemônica dentro da Península Ibérica e quiçá perante a cristandade latina e o mundo muçulmano: "rei de toda Espanha e Andaluzia", como versa o trecho da fonte. Além disso, o jogo de temporalizações que o rei constrói no prólogo evidencia sua percepção temporal e a instrumentalização da memória, de forma a colocar o Picatrix na transcendência das identidades religiosas/culturais. Na frase "Este é o trabalho perfeito terminado no ano do Senhor 1256, de Alexander 1568, de Cesar 1295 e dos árabes 655", o monarca transcende também sua limitação de rei dos cristãos, pois seu trono e sabedoria estão assentados sobre o poder e conhecimento dos gregos, dos romanos e dos muçulmanos. Por isso, o Picatrix "é o trabalho perfeito", assim como o rei sábio o é.

A relação entre micro e macrocosmo presente nas fórmulas mágicas do Picatrix também fundamentam a grande obra legislativa afonsina, as Siete Partidas, a qual evidencia como o projeto político e social de Afonso está prenhe da experiência dos "filósofos antigos". Principalmente na ley I, titulo IX, partida II podemos ler a relação do corpo (microcosmo) como o "mundo mayor" (macrocosmo) e de como o reino foi "semelhado" ao corpo por Aristóteles. ${ }^{20}$ De forma que, assim como todos os membros e órgãos do corpo obedecem à "cabeça", assim todos os membros da sociedade devem obedecer ao rei. Ou seja, reconhecer o seu lugar dentro da hierarquia do reino seria o mesmo que reconhecer o seu lugar na hierarquia do universo. Consequentemente, mouros e judeus possuíam também um lugar neste corpo e poderiam ser aliados do rei, seu protetor, perante os levantes da alta nobreza castelhana. A mesma nobreza que contestava os acometimentos de Afonso no sentido de instaurar a centralização do poder intrarregional na coroa castelhana.

\section{Considerações finais}

Exatamente por se tratar de uma cultura de presença do passado, é possível perceber que os projetos (expectativas) do reinado de Afonso $X$ são fortemente constituídos pelas experiências/tradições/memórias. Essa fluidez temporalizada das expectativas e experiências forma a historicidade da fonte, ao mesmo tempo em que, constitui a abertura para a compreensão do fato histórico. Na transculturalidade que a fonte faz presente, a tradução dos livros de astromagia serve também aos propósitos do monarca castelhano, pois quando o Picatrix esclarece e revela a ordem do universo, ele também fundamenta melhor o projeto político e social de Afonso X.

Quando Valdei Araújo coloca que "as condições que prefiguram a escrita da história não são apenas condições historiográficas, mas são também ontológicoexistenciais" (ARAÚJO 2013, p. 41), é inevitável para o medievalista pensar na percepção de mundo baseada nesta relação e experimentada pelo Ser no medievo. Ao procurarmos outras expressões da filosofia medieval - para além dos Pais da Igreja cristã - como é o caso dos livros de astromagia, encontramos

\footnotetext{
${ }_{20}$ Partida II, Titulo IX, Ley I. In: ALFONSO EL SABIO. Las Siete Partida. (1555, nova edição 2004).
} 
postulados como este: "o ser humano é um pequeno mundo que corresponde ao um grande mundo, pois sua essência é uma partícula perfeita [...] e quem não atinge este nível de entendimento, não pode ser chamado de ser humano, mesmo que tenha a forma de um". ${ }^{21}$ Esta compreensão simbiótica entre o Ser (microcosmo) e o Mundo (macrocosmo) dá evidências à compreensão de Gumbrecht de que no medievo há uma cultura de presença do passado. Pois, o pensamento medieval astromágico compreende com facilidade a simultaneidade do Ser: já que o macrocosmo está presente no interior do microcosmo, a função da magia seria restabelecer a não-dissociação entre Ente e Ser, desfazendo, através de rituais, os limites temporais e espaciais, libertando e abrindo os portais para um universo mais profundo (do mundo da pre-sença?).

Refletir sobre os conceitos de temporalidade, historicidade e presença, nos faz perceber a necessidade da ciência histórica em familiarizar-se com o pensamento filosófico para que se possamos entender o passado de forma não dissociada do futuro.

\section{Referências bibliográficas}

ALFONSO EL SABIO. Astromagia (Ms.Reg.lat.1283a). Napoli: Liguori, 1992.

. Lapidario. Según el manuscrito escurialense h.I 15. Ed. Rafael Lapesa. Madrid: Gredos, 1981.

Las Siete Partida. Ed. Gregório Lopez. Madrid, 2004 [1555].

APPETITI. Emanuela. Translatio Studiorum in the activity of the institute for the preservation of medical traditions. Medievalia, v. 16, p. 13-21, 2013.

ARAÚJO, Valdei Lopes. História da historiografia como analítica da historicidade.

História da Historiografia, n. 12, p. 34-44, 2013.

BAKTHIN, Mikail. A cultura popular na Idade Média e no Renascimento. São Paulo: Hucitec-UnB, 1987.

BERTOMEU, Fabio Vélez. Translatio studiorum: breve historia de la transmisión de los saberes. Mutatis Mutandis, v. 6, n. 1, p. 126-138, 2013.

CASANOVA, Marco Antônio. Compreender Heidegger. Petrópolis: Vozes, 2015.

DÍES BRASA, Mariano. Alfonso X El Sabio y los Traductores Españoles. Cuadernos Hispano-americanos, n. 410, p. 21-33, 1984.

Diplomatario Andaluz de Alfonso X. Ed. Manuel Gonzálvez Jimenez. Sevilla: El Monte, 1991.

DREWS, Wolfram. Die Karolinger und die Abbasiden von Bagdad. Legitimationsstrategien frühmittelalterlicher Herrscherdynastien im

\footnotetext{
${ }_{21}$ Tradução livre da autora a partir da tradução alemã do Gayat al-Hakim: "Wer aber hinter dieser Stufe zuruckbleibt, kann nicht als Mensch gezahlt werden, wenn er auch die außere Gestalt eines Menschen hat; denn er achtet nicht auf das wahre Wesen seines Seins, daß er namlich eine kleine Welt ist, die einer großen Welt entspricht. Denn sein Wesen besteht darin, daß er ein volkommenes Partikulare [...]". Gayat al-Hakim, Tratado I, capítulo 6, p. 45, § 9-16).
} 
transkulturellen Vergleich. Berlin: Akademie Verlag, 2009.

DUBY, George. As três ordens ou o imaginário do feudalismo. Lisboa: Estampa, 1994.

ESCUDÉ, Carlos. Neoplatonismo y pluralismo filosófico medieval: un enfoque politológico. Buenos Aires: Universidad de Cema, 2011.

FIGAL, Gunter. Introdução a Martin Heidegger. Trad. Vinícius Lopes. Rio de Janeiro: Via Verita, 2016.

FLORIDO, F. Léon. Translatio Studiorum: translado de los libros y diálogo de las civilizaciones en la Edad Media. Revista General de Información y Documentación, v. 15, n. 2, p. 51-77, 2005.

FROEYMAN, Anton. Frank Ankersmit and Eelco Runia: the presence and the otherness of the past. Rethinking History, v. 16, n. 3, p. 393-415, 2012.

GARCÍA AVILÉS, Alejandro. Alfonso $X$ y la tradición de la magia astral. In: MONTOYA MARTINEZ, J.; DOMÍNGUEZ RODRÍGUEZ, A. (Org.). EI Scriptorium Afonsí: de los Libros de Astrología a las "Cantigas de Santa María". Madrid: Complutense, 1999, p. 83-103.

- Produção de Presença: o que o sentido não consegue transmitir. Tradução de Ana Isabel Soares. Rio de Janeiro: Contraponto: Ed. PUCRio, 2010.

GUREVICH, Aron. I.. As categorias da cultura medieval. Lisboa: Caminho, 1991.

HEIDEGGER, Martin. Sein und Zeit. Tübingen: Max Niemeyer Verlag, 2006 [1927].

. Ser e tempo. Tradução de Márcia Sá Cavalcanti Schubach. 13. ed.

Petrópolis: Vozes, 2005.

KOSELLECK, Reinhart. Zeitschichten. Studien zur Historik. Mit einem Beitrag von Hans-Georg Gandamer. Frankfurt am Main: Suhrkamp, 2000.

Estratos do Tempo: estudos sobre Historia. Rio de Janeiro: Contra Ponto, 2014.

Futuro passado: contribuição à semântica dos tempos históricos.

Trad. Wilma Patrícia Mass, Carlo Almeida Pereira. 3. ed. Rio de Janeiro: Contra Ponto, 2012.

LE GOFF, Jacques. O imaginário medieval. Lisboa: Estampa, 1994.

LE GOFF, Jacques. O maravilhoso e o cotidiano no ocidente medieval. Lisboa: Edições 70, 1983.

LUPI, João; GOLLNICK, Silvania. A Teoria Emanacionista de Plotino. Scintila, v. 5, n. 1, p. 13-30, 2008.

MEEDER, Sven. The Irish Foundations and the Carolingian World. In: Settimane di Studio della Fondazione Centro Italiano di Studi Sull'alto 
Medioevo. L'Irlanda e Gli Irlandesi nell'alto medioevo. Spoleto: Centro Italiano di Studi sull'alto Medioevo, 2010, p. 468-493.

OTTO VON FREISING. Chronik oder die Geschichte der Zwei Staaten. Berlin: Rütten \& Loening, 1960.

PEREIRA, Rosalie Helena de Souza. Do Ocidente para o Oriente: Harrān, último reduto pagão e centro de transmissão do pensamento grego para o mundo islâmico. In: De BONI, L. A.; PICH, R. H. (Org.). A recepção do pensamento greco-romano, árabe e judaico pelo Ocidente medieval. Porto Alegre: EDIPUCRS, 2004, p. 71-88. v. 1.

Picatrix. Das Ziel der Weisen von Pseudo-Magriti. Trad. e ed. Hellmut Ritter e Martin Plessnaer. London: The Warburg Institute, 1962 [1933]. (Studies of the Warburg Institut, 27).

Picatrix. The Latin Version of the Ghayat Al-Hakim. Trad. e ed. David Pingee. London: The Warburg Institute, 1986.

PINGREE, David, Some of the Sources of the Ghayat al-Hakim. Journal of the Warburg and Courtauld Institutes, v. 43, p. 1-15, 1980.

. The Sabians of Harran and the Classical Tradition. International Journal of the Classical Tradition, v. 9, p. 8-35, 2002.

RUNIA. Eelco. Presence. History and Theory, v. 45, n. 1, p. 1-29, 2006.

200 - Moved by the Past: Discontinuity and Historical Mutation. New York: Columbia University Press, 2014.

RÜSEN, Jörn (Org.). Westliches Geschichtsdenken. Eine interkulturelle Debatte. Göttingen: Vandenhoeck und Ruprecht, 1999.

. Como dar Sentido ao Passado: questões de meta-história. História e Historiografia, n. 2, p. 163-209, 2009.

SEIBT, Cezar Luís. Temporalidades e propriedade em Ser e Tempo de Heidegger. Revista de Filosofia Aurora, v. 22, n. 30, p. 247-266, 2010.

SENKO, Elaine Cristina. Afonso X, o Sábio (1221-1284) e a Recepção da Translatio Studiorum na Idade Média viva. Revista Litteris, n. 14, p. 238-251, 2014.

SGARDI, Marco. (Ed.). Translatio Studiorum ancient, medieval and modern bearers of intellectual History. Leiben; Boston: Brill, 2012. (Brill' Studies in Intellectual History, v. 27).

SILVEIRA, Aline Dias. A Trama da História na concepção de povo nas Siete Partidas. Revista Diálogos Mediterrânicos, n. 7, p. 66-83, 2014.

SILVEIRA, Aline Dias. Fronteiras da Tolerância e Identidades na Castela de Afonso X. In: FERNANDES, Fátima Regina. Identidades e Fronteiras no Medievo Ibérico. Curitiba: Juruá, 2013, p. 127-149. 
- Saber em movimento na obra andaluza Gāyat al-hakīm, o Picatrix: problematização e propostas. Diálogos Mediterrânicos, n. 9, p. 169$188,2015$.

STEIN, Ernildo. Em busca da linguagem para um dizer não-metafísico. Natureza Humana, v. 6, n. 2, p. 289-304, 2004.

Introdução ao pensamento de Martin Heidegger. Porto Alegre: EDIPUCRS, 2002.

TELLES, Marcus Vinícius de Moura. Presença do passado e produção de sentido: Hayden White e Eelco Runia. In: XXVIII Simpósio Nacional de História/ ANPUH. Anais... Florianópolis, 2015, p. 1-16.

VETTER, Helmuth. Grundhiss Heidegger. Ein Handbuch zu Leben und Werk. Hamburg: Felix Meiner Verlag, 2014.

ZUMTHOR, Paul. La medida del mundo. Madrid: Catedra, 1984. 